Bove and colleagues ${ }^{4}$ reported the case of a patient with heterotaxia and single-ventricle physiology successively undergoing pulmonary arterial banding at 8 months of age, repair of pulmonary vein stenosis at 15 months of age, and a fenestrated TCPC at 5 years of age. Clinically, management of that child's condition was troublesome because of pulmonary and systemic venous hypertension. In light of the grim prognosis of pulmonary vein stenosis in general, however, the case reports a long-term successful outcome of a TCPC after repair of pulmonary vein stenosis. Our patient underwent repair of pulmonary vein stenosis and also repair of nonconfluent pulmonaryartery-supplied bilateral patent ductus arteriosus. We consider our case to be unprecedented.

\section{References}

1. Michielon G, Ghazagozloo F, Julsrud PR, Danielson GK, Puga FL. Modified Fontan operation in the presence of anomalies of systemic and pulmonary venous connection. Circulation. 1993;88:141-8.

2. Heinemann MK, Hanley FL, Van Praagh S, Fenton KN, Jonas RA, Mayer JE, et al. Total anomalous pulmonary venous drainage in newborns with visceral heterotaxy. Ann Thorac Surg. 1994;57:88-91.

3. Gaynor JW, Collins MH, Rychil J, Gaghan JP, Spray TL. Long-term outcome of infants with single ventricle and total anomalous pulmonary venous connection. J Thorac Cardiovasc Surg. 1999;117:506-14.

4. Bove T, Demanet H, Dessy H, Viart P, Deuvaert FE. Cavopulmonary connection after repair of pulmonary vein stenosis. Ann Thorac Surg. 2001;71:725-7.

\title{
Primary cardiac ancient schwannoma
}

Davinder S. Jassal, MD, FRCPC, ${ }^{a}$ J. F. Légaré, MD, FRCSC, ${ }^{b}$ Brian Cummings, MD, FRCPC, ${ }^{c}$ R. C. Arora, MD, ${ }^{\text {b,d }}$

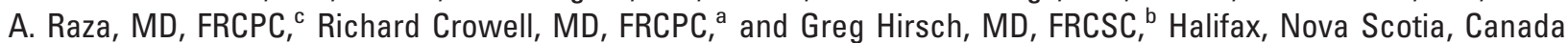

A

49-year-old woman with a history of mitral valve prolapse presented with pleuritic chest discomfort of 2 weeks' duration. During the follow-up period, echocardiography and magnetic resonance imaging (MRI) confirmed a right atrial mass measuring $5 \times 3 \mathrm{~cm}$. After cardiopulmonary bypass, the histologic and immunohistochemical features were consistent with an ancient cardiac schwannoma. To the best of our knowledge, there have been only 5 previous cases of primary cardiac schwannomas described in the literature, all presenting with symptomatic pericardial effusions; our case was notable for its rather benign presentation.

\section{Clinical Summary}

A 49-year-old woman with a history of mitral valve prolapse presented with a 2-week history of episodic pleuritic chest dis-

\footnotetext{
From the Section of Cardiology, Department of Medicine, ${ }^{a}$ the Section of Cardiac Surgery, Department of Surgery, ${ }^{\mathrm{b}}$ the Division of Anatomical Pathology, Department of Pathology and Laboratory Medicine, ${ }^{\mathrm{c}}$ and the Department of Anatomy and Neurobiology, ${ }^{\mathrm{d}}$ Dalhousie University, Halifax, Nova Scotia, Canada.

Received for publication July 12, 1001; accepted for publication July 22, 2002.

Address for reprints: Davinder S. Jassal, MD, FRCPC, Department of Cardiology, Queen Elizabeth II Health Sciences Centre, Room 2134-1796 Summer St, Halifax, Nova Scotia, Canada B3K 6A3 (E-mail: umjassal@hotmail.com).

J Thorac Cardiovasc Surg 2003;125:733-5

Copyright $\odot 2003$ by The American Association for Thoracic Surgery $0022-5223 / 2003 \$ 30.00+0$

doi: $10.1067 / \mathrm{mtc} .2003 .26$
}

comfort. She denied symptoms of exertional dyspnea, orthopnea, palpitations, syncope, or infection or any risk factors for thromboembolism.

The patient was afebrile and normotensive and had no signs of systemic infection. The cardiorespiratory examination was remarkable only for signs of mitral valve prolapse with mild mitral regurgitation. There was no calf or thigh swelling or tenderness.

The complete blood count, electrolyte level, liver function test results, cardiac enzyme level, coagulation parameters, and urinalysis results were within normal limits. Electrocardiography revealed sinus bradycardia with a normal chest radiograph. An echocardiographic examination revealed mild prolapse of the anterior mitral leaflet, mild mitral regurgitation, and a mass measuring $5 \times 3 \mathrm{~cm}$ in size occupying the entire right atrium. Additionally, MRI confirmed a right atrial mass of $5 \times 3 \mathrm{~cm}$ (Figure 1). These diagnostic tests were unable to discern whether the mass was intracavitary or extrinsic in nature. Mammography, bone scan, and infused computed tomography of the abdomen and pelvis were also performed to rule out metastatic malignant disease; results of these studies were normal. A coronary catheterization revealed normal coronary vasculature.

During cardiopulmonary bypass, the mass was identified as originating from the right atrium adjacent to the atrioventricular groove and was successfully removed (Figure 2, A). The specimen consisted of an encapsulated ovoid tumor of $6.4 \times 5.5 \times$ $3.4 \mathrm{~cm}$, with a weight of $70.9 \mathrm{~g}$ and a heterogeneous yellow and white appearance on cut section (Figure 2, B). On microscopy, the tumor consisted of spindled tumor cells with an eosinophilic cytoplasm and elongated nuclei, some demonstrating a wavy appearance (Figure 3,A). Histologic and immunohistochemical features were consistent with an ancient schwannoma (Figure 3, $B)$. 


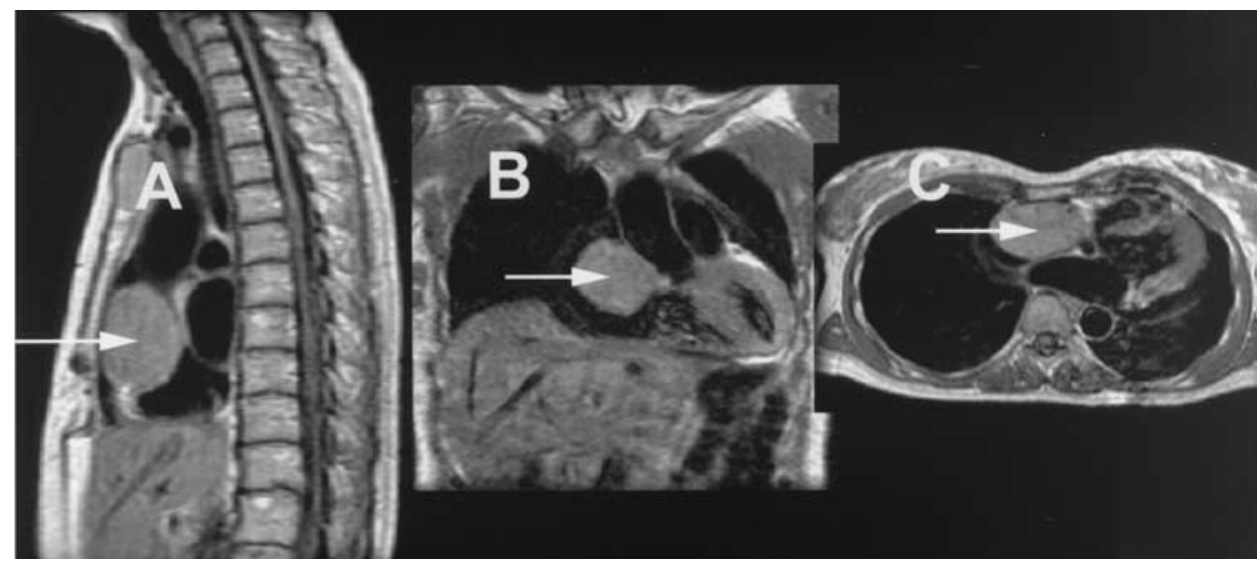

Figure 1. Magnetic resonance images of the thorax showing a large heterogeneous mass originating in the right atrium. T1W sagittal (A), coronal (B), and axial (C) images are shown, respectively.

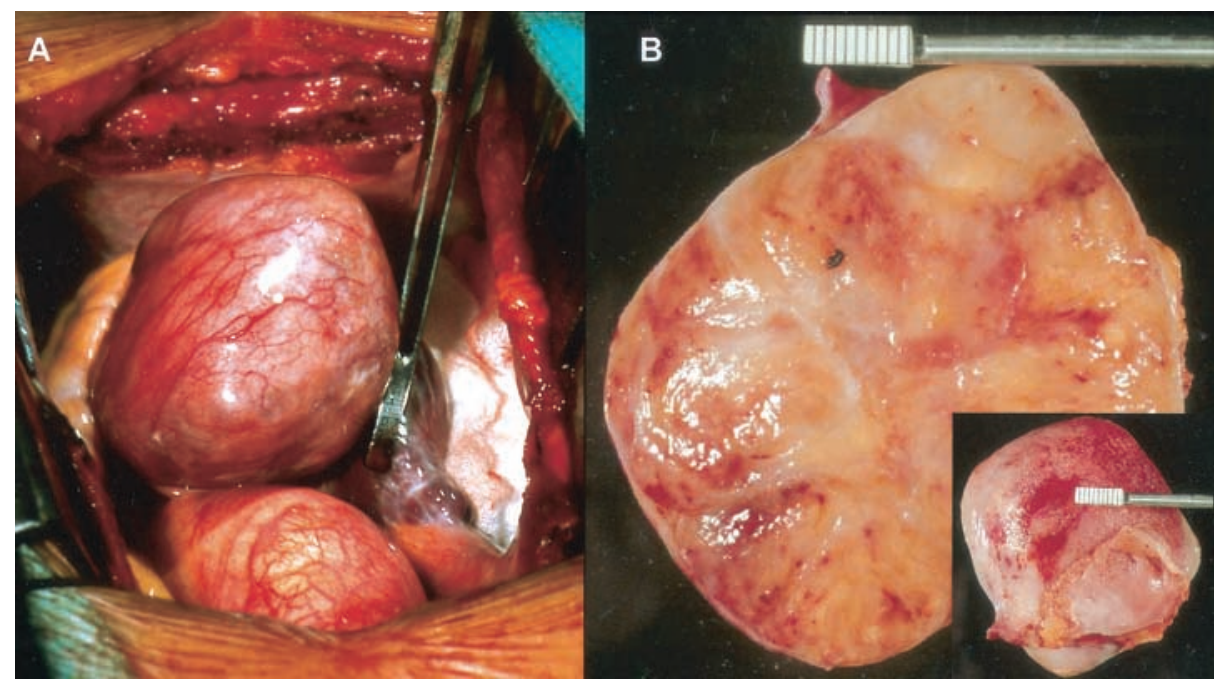

Figure 2. A, Intraoperative photograph of the tumor mass originating from the right atrium adjacent to the atrioventricular groove. B, Cut section of encapsulated tumor with a heterogeneous appearance and pinpoint hemorrhages. Inset, External view of the encapsulated tumor and fragment of the atrial wall.

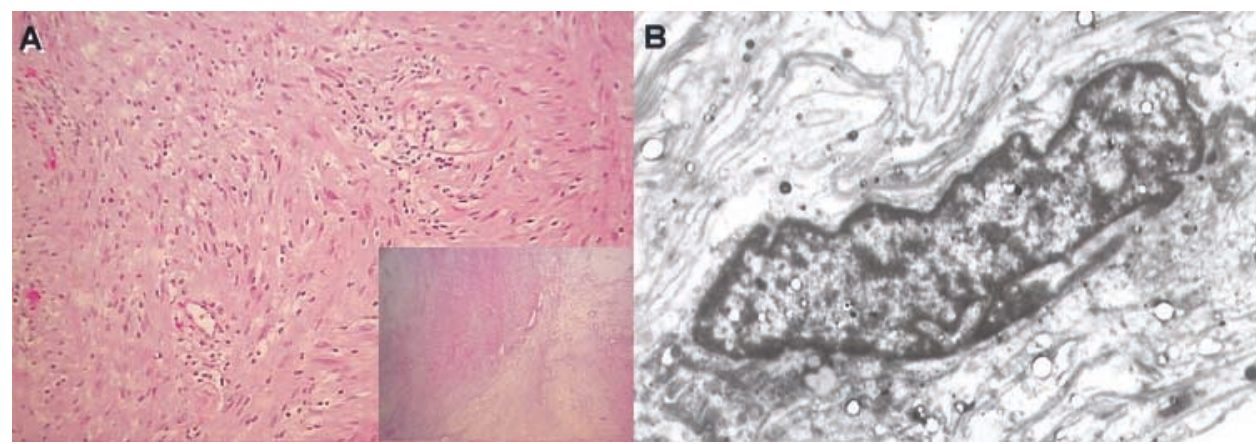

Figure 3. A, Hypercellular area containing tumor cells with eosinophilic cytoplasm and elongated nuclei. (Hematologic and eosin stain; original magnification $160 \times$.) Inset, Hypercellular (Antoni A) and hypocellular (Antoni B) areas of the tumor. B, Irregular tumor nuclei with undulating cytoplasmic processes coated on their free surfaces by external lamina. (Original magnification $5000 \times$.) 


\section{Discussion}

Primary cardiac tumors are an extremely rare diagnostic entity. ${ }^{1}$ The clinical outcome depends not only on the histology of the tumor but also on its location and rate of growth in addition to how promptly it is detected and appropriately treated. Although the first symptoms are often constitutional, cardiovascular symptoms, including dyspnea, orthopnea, dependent edema, and thromboembolism, are often the presenting manifestations. ${ }^{1,2}$

Although left atrial myxomas are by far the most common primary cardiac tumors diagnosed, our patient presented with a rather unique ancient cardiac schwannoma. The nervous system of the heart resides in the epicardial fat associated with the atria and ventricles and contains both myelinated and unmyelinated axons. ${ }^{3}$ Associated neurons are thus capable of undergoing pathologic and functional changes in cardiac disease, as in our patient. A MEDLINE review of the literature published between 1966 and 2002 revealed only 5 previously described cases of primary cardiac schwannomas, all of which presented with symptomatic pericardial effusions; our case was notable for its rather benign presentation. . $^{-5}$

The diagnosis of a primary cardiac neoplasm is best screened by means of transthoracic echocardiography. Whereas the identi- fication of endocardial-based lesions in the atria is best delineated with transesophageal echocardiography, the assessment of pericardiac masses remains the strength of MRI. ${ }^{1}$ Once a diagnosis is made, the patient should have prompt removal of the cardiac neoplasm after an appropriate work-up to rule out metastatic disease of the heart and pericardium. The first step toward the appropriate diagnosis of a cardiac neoplasm remains when the clinician considers it in the differential diagnosis.

\section{References}

1. Salcedo E, Cohen G, White R, et al. Cardiac tumors: diagnosis and management. Curr Probl Cardiol. 1992;17:78-137.

2. Hashimoto T, Eguchi S, Nakayama T, et al. Successful removal of massive cardiac neurilemoma with cardiopulmonary bypass. Ann Thorac Surg. 1998;66:553-5.

3. Monroe B, Federman M, Balogh K. Cardiac neurilemoma. Report of a case with electron microscopy examination. Arch Pathol Lab Med. 1984;108:300-4.

4. Kodama M, Aoki M, Sakai K. Images in cardiovascular medicine. Primary cardiac neurilemoma. Circulation. 1995;92:274-5.

5. Morishita T, Yamazaki J, Oshawa H, et al. Malignant schwannoma of the heart. Clin Cardiol. 1998;11:126-30. 